Fixed Point Theory, 19(2018), No. 2, 801-822

DOI: $10.24193 /$ fpt-ro.2018.2.59

http://www.math.ubbcluj.ro/ nodeacj/sfptcj.html

\title{
ITERATIVE METHODS FOR SYSTEM OF VARIATIONAL INCLUSIONS INVOLVING ACCRETIVE OPERATORS AND APPLICATIONS
}

\author{
XIAOPENG ZHAO*, D.R. SAHU** AND CHING-FENG WEN*** \\ ${ }^{*}$ Department of Mathematics, Tianjin Polytechnic University, Tianjin 300387, P. R. China \\ E-mail: zhaoxiaopeng.2007@163.com \\ ** Department of Mathematics, Banaras Hindu University, Varanasi-221005, India \\ E-mail: drsahudr@gmail.com \\ *** Corresponding author \\ Center for Fundamental Science, and Research Center for Nonlinear Analysis and Optimization \\ Kaohsiung Medical University, Kaohsiung 80702, Taiwan \\ and \\ Department of Medical Research, Kaohsiung Medical University Hospital \\ Kaohsiung 80702, Taiwan \\ E-mail: cfwen@kmu.edu.tw
}

\begin{abstract}
The purpose of this paper is to study existence and approximation of solutions of system of variational inclusions involving multi-valued $H$-accretive and single-valued accretive operators over two different closed convex subsets of a Banach space. The convergence analysis of two proposed iteration processes for approximating solutions will be conducted within the conceptual framework of the "altering point technique" without uniform convexity of underlying spaces. This technique should make existing or new results in solving system of variational inequalities and variational inclusions.

Key Words and Phrases: Accretive operator, altering points, Mann iteration method, Lipschitz mapping, resolvent operator, variational inclusion problem.
\end{abstract}

2010 Mathematics Subject Classification: 47H09, 47H10, 47J25.

Acknowledgements. The corresponding author was partially supported by the grant MOST 105-2115-M-037-001, and the grant from Research Center for Nonlinear Analysis and Optimization, Kaohsiung Medical University, Taiwan.

\section{REFERENCES}

[1] R.P. Agarwal, D. O'Regan, D.R. Sahu, Fixed point theory for Lipschitzian-type mappings with applications, Series: Topological Fixed Point Theory and Its Applications, Vol. 6, Springer, New York, 2009.

[2] J. Douglas, H.H. Rachford, On the numerical solution of heat conduction problems in two and three space variables, Trans. Amer. Math. Soc., 82(1956), 421-439.

[3] K. Goebel, S. Reich, Uniform Convexity, Hyperbolic Geometry and Nonexpansive Mappings, Marcel Dekker, Inc., New York, 1984. 
[4] Y.P. Fang, N.J. Huang, H-Monotone operator and resolvent operator technique for variational inclusions, Appl. Math. Comput., 145(2003), 795-803.

[5] P.L. Lions, B. Mercier, Splitting algorithms for the sum of two nonlinear operators, SIAM J. Numer. Anal., 16(1979), 964-979.

[6] S.Y. Liu, H.M. He, Approximating solution of $0 \in T(x)$ for an $H$-accretive operator in Banach spaces, J. Math. Anal. Appl., 385(2012), 466-476.

[7] P.E. Mainge, Approximation method for common fixed points of nonexpansive mappings in Hilbert spaces, J. Math. Anal. Appl., 325(2007), 469-479.

[8] N.D. Nguyen, N. Buong, An iterative method for zeros of accretive mappings in Banach spaces, J. Nonlinear Funct. Anal., 2016(2016), Article ID 15, 1-17.

[9] D.H. Peaceman, H.H. Rachford, The numerical solution of parabolic and elliptic differential equations, J. Soc. Industrial Appl. Math., 3(1955), 28-41.

[10] X. Qin, J.C. Yao, Weak convergence of a Mann-like algorithm for nonexpansive and accretive operators, J. Inequal. Appl., 2016(2016), Article ID 232, 1-9.

[11] X. Qin, B.A. Bin Dehaish, S.Y. Cho, Viscosity splitting methods for variational inclusion and fixed point problems in Hilbert spaces, J. Nonlinear Sci. Appl., 9(2016), 2789-2797.

[12] X. Qin, S.Y. Cho, S.M. Kang, Convergence of an iterative algorithm for systems of variational inequalities and nonexpansive mappings with applications, J. Comput. Appl. Math., 233(2009), 231-240.

[13] D.R. Sahu, Q.H. Ansari, J.C. Yao, The prox-Tikhonov-like forward-backward method and applications, Taiwanese J. Math., 19(2015), 481-503.

[14] D.R. Sahu, Altering points and applications, Nonlinear Studies, 21(2014), no. 2, 349-365.

[15] D.R. Sahu, Applications of the S-iteration process to constrained minimization problems and split feasibility problem, Fixed Point Theory, 12(2011), 187-204.

[16] P. Tseng, Applications of a splitting algorithm to decomposition in convex programming and variational inequalities, SIAM J. Control Optim., 29(1991), no. 1, 119-138.

[17] R.U. Verma, General convergence analysis for two-step projection methods and applications to variational problems, Appl. Math. Lett., 18(2005), 1286-1292.

[18] H.K. Xu, Inequalities in Banach spaces with applications, Nonlinear Anal., 16(1991), no. 12, $1127-1138$.

[19] Y.H. Yao, Y.C. Liou, S.M. Kang, Two-step projection methods for a system of variational inequality problems in Banach spaces, J. Global Optim., 55(2013), 801-811.

[20] L.C. Zeng, S.M. Guu, J.C. Yao, Characterization of H-monotone operators with applications to variational inclusions, Computers Math. Appl., 50(2005), 329-337.

Received: March 14, 2016; Accepted: August 30, $201 \%$. 
